Омаров Ш. А. Махмудов К. Д.

\title{
ЭКСПЕРИМЕНТАЛЬНЫЕ ИССЛЕДОВАНИЯ МАГНИТНО-ЭЛАСТОИМПУЛЬСНОЙ ФОРМОВКИ
}

Основной целью экспериментальных исследований магнитно-эластоимпульсной формовки (МЭИФ) является определение параметров разрядного контура, в частности разрядного тока, напряженности магнитного поля в зазоре между индуктором и подвижным элементом, параметров давления в эластичной среде при деформировании заготовки, а также параметров прогиба заготовки и толщиной деформации. Данные измерения должны выполняться синхронно для того, чтобы осуществить проверку корректности расчетной модели. Кроме этого необходимо оценить параметры кривой деформационного упрочнения материала заготовки и аппроксимировать ее, чтобы можно было задавать их в качестве исходных данных в расчетную модель [1-3].

Трудностью таких экспериментальных исследований является измерение давлений в эластичной среде. Для решения этой задачи предлагается формующую матрицу жестко совместить с подвижным элементом, а датчик давления установить с обратного торца эластичного блока.

Результаты экспериментальных исследований позволят оценить корректность расчетной модели. Чтобы правильно віполнить такое сравнение, необходимо оценить погрешности отдельных измерителей, а также осуществить тарировку всех измерительных преобразователей.

В основу данных измерений положены методы измерения давлений, конструкции датчиков давления и их тарировка, методы измерения разрядного тока поясом Роговского, напряженности магнитного поля - индукционными датчиками $[4,8]$.

Данные пояса Роговского и интегрирующей $\mathrm{RC}-$ цепочки представлены в табл. 1.

Таблица 1

Параметры пояса Роговского и интегрирующей RC

\begin{tabular}{|c|c|c|c|c|c|}
\hline № П/П & \multicolumn{2}{|c|}{ Наименование параметров } & Обозначение & Ед. измерения & Значение \\
\hline \multirow{4}{*}{1} & \multirow{4}{*}{$\begin{array}{c}\text { Параметры пояса } \\
\text { Роговского }\end{array}$} & Число витков & $\mathrm{n}_{\mathrm{k}}$ & & 1486 \\
\hline & & Индуктивность & $\mathrm{L}$ & мкГ & 643,5 \\
\hline & & $\begin{array}{c}\text { Сопротивление } \\
\text { катушки }\end{array}$ & $\mathrm{R}_{\mathrm{p}}$ & Ом & 23,2 \\
\hline & & $\begin{array}{c}\text { Чувствительность } \\
\text { пояса }\end{array}$ & $\mathrm{K}_{\mathrm{r}}$ & мкГ & 0,432 \\
\hline \multirow{4}{*}{2} & \multirow{4}{*}{$\begin{array}{l}\text { Параметры } \\
\text { RC-цепочки }\end{array}$} & Сопротивление & $\mathrm{R}$ & кОм & 13,0216 \\
\hline & & Емкость & $\mathrm{C}$ & МкФ & 0,251 \\
\hline & & & $\tau_{\mathrm{n}}$ & Mc & 3,25 \\
\hline & & $\begin{array}{c}\text { Сопротивление } \\
\text { входа осциллографа }\end{array}$ & $\mathrm{R}_{\text {оц }}$ & МОм & 0,5 \\
\hline
\end{tabular}

Характеристики индукционного датчика представлены в табл. 2.

Таблица 2

Характеристики индукционного датчика

\begin{tabular}{|c|c|c|c|c|c|}
\hline L, мM & h, мм & N & U, mB & I, A & $\mathrm{K}_{\mathrm{h}}$ \\
\hline 11,6 & 0,60 & 20 & 2,8 & 10 & $1,2 * 10$ \\
\hline
\end{tabular}

Методика экспериментальной оценки магнитного поля индуктора при формовке построена на основе обработки измерений напряженности магнитного поля вдоль радиального направления спирали при помощи индукционного датчика и расчета коэффициента эффективности. 
Предложена система безразмерных параметров, влияющих на коэффициент эффективности. На основе обработки экспериментальных данных получена эмпирическая зависимость коэффициента эффективности от безразмерных параметров. Данная зависимость может быть использована в практике расчетов технологического устройства и технологий МЭИФ.

В условиях мелкосерийного производства деталей из тонколистовых материалов экономически эффективны технологии формовки, использующие один жесткий рабочий инструмент. Роль второго инструмента обычно выполняет эластичная среда, в качестве которой зачастую используют полиуретаны. $\mathrm{K}$ такой технологии относится магнитноэластоимпульсная формовка (МЭИФ) [5-8].

Схема установки МЭИФ показана на рис. 1. При электрическом разряде конденсаторной батареи магнитно-импульсной установки (МИУ) на плоский спиральный индуктор 1 в зазоре между спиралью индуктора и подвижным элементом 2, выполненным из материала с высокой электропроводностью, возникает сильное импульсное магнитное поле. При перемещении подвижного элемента под действием электромагнитного усилия в замкнутом контейнере 5 с эластичной средой 4 возникает импульсное давление, которое воздействует на объект нагружения 3 (заготовка с инструментом).

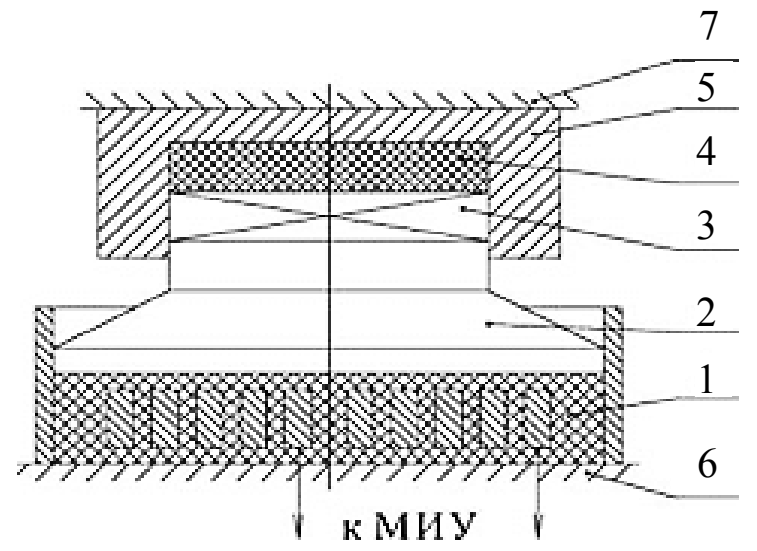

Рис. 1. Схема магнитно-эластоимпульсной формовки:

1 - плоский индуктор; 2 - подвижный элемент; 3 - объект нагружения; 4 - эластичная среда; 5 - контейнер; 6, 7 - механический прижим

Одной из наиболее важных задач при проектировании технологических устройств МЭИФ является повышение эффективности преобразования энергии. В значительной степени это определяется эффективностью системы «индуктор - подвижный элемент». Преобразование импульсного давления самим подвижным элементом - механическим концентратором можно оценить относительно просто.

Поэтому цель нашей работы - экспериментальная оценка эффективности системы «индуктор - подвижный элемент». Экспериментальные данные необходимы также для оценки корректности расчетной модели при математическом моделировании.

Электромагнитное давление может быть определено по величине напряженности магнитного поля в конкретной точке зазора между спиралью индуктора и подвижным элементом, где помещается датчик. Для измерения напряженности магнитного поля могут применяться датчики, основанные, например, на эффектах Холла, Фарадея, Зеемана, изменения удельного сопротивления и др. Однако с точки зрения удовлетворения габаритных требований, простоты конструкции и применения, точности измерения в условиях МЭИФ наиболее целесообразно использовать индукционный датчик (рис. 2-4), представляющий собой катушку связи, в которой наводится напряжение, если поместить ее в изменяющийся во времени магнитный поток.

Типичный индукционный датчик для измерения сильных импульсных магнитных полей в условиях МЭИФ представляет собой катушку из 15-25 витков медной изолированной проволоки толщиной не более 0,05 мм, намотанных на каркас из лавсанового диэлектрика. 


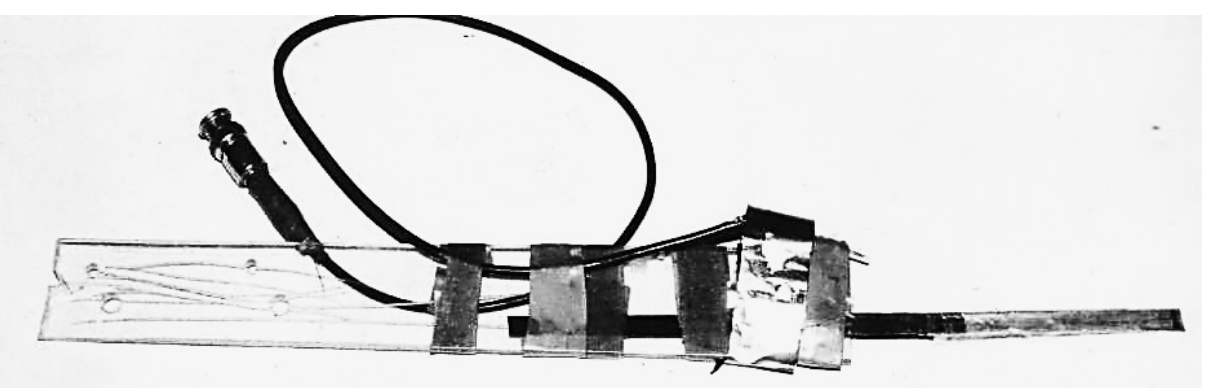

Рис. 2. Внешний вид индукционного датчика с интегрирующей RC-цепочкой

Величина изоляционного зазора между индуктором и подвижным элементом до момента нагружения обычно не превышает 0,5-1,0 мм. Поэтому толщина датчика должна быть менее 0,5 мм. Размеры катушки вдоль силовых линий магнитного поля также должны быть достаточно малыми, чтобы усреднение вдоль этого направления не приводило к значительной погрешности измерения. Длина катушки задается в пределах 1-2 мм, а ширина 5-10 мм. Для уменьшения паразитной индуктивности подводов провода перекручиваются и подсоединяются к коаксиальному кабелю, а для стабилизации параметров катушка и подводы пропитываются клеем.

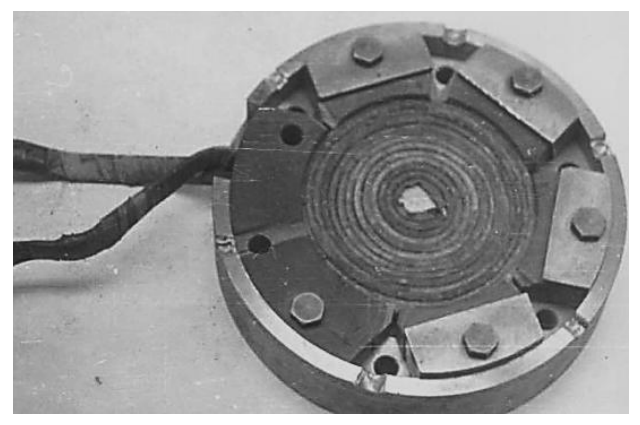

Рис. 3. Внешний вид плоского спирального индуктора

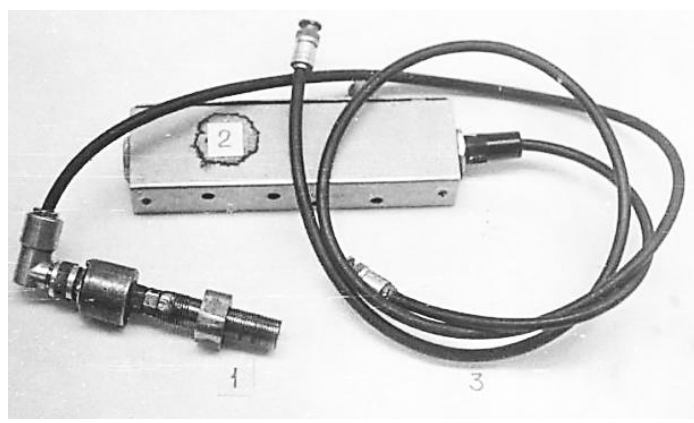

Рис. 4. Внешний вид пьезоэлектрического датчика с акустическим стержнем

Для индукторных систем, используемых для МЭИФ, характерно незначительное искривление силовых линий магнитного поля. Поэтому объемное электромагнитное усилие может быть заменено электромагнитным давлением. При разряде конденсаторной батареи на спираль индуктора в зазоре между спиралью и подвижным элементом из электропроводного материала возникает импульсное магнитное поле с напряженностью $H$, наводящее вихревые токи в поверхностном слое материала подвижного элемента, что приводит к силовому воздействию на него. Для подвижного элемента, толщина которого значительно превышает скин - слой магнитного потока, просачивание поля практически отсутствует.

Для получения на осциллографе сигнала, пропорционального напряженности магнитного поля на выход катушки перед осциллографом можно поставить RC-интегратор. Если постоянная времени интегрирования $T=\mathrm{RC}$ намного превышает длительность сигнала, а входное сопротивление осциллографа намного больше сопротивления интегратора, тогда напряженность поля может быть определена по величине напряжения $U(t)$ сигнала на осциллографе.

Схема измерений представлена на рис. 5. При разряде конденсаторной батареи $C$ магнитно-импульсной установки 4 по спирали индуктора 1 протекает импульсный ток, а в изоляционном зазоре 2 между спиралью индуктора и подвижным элементом 3 возникает магнитное поле. Напряженность магнитного поля измеряется индукционным датчиком 6 с интегрирующей RC-цепочкой 7. Измерение разрядного тока осуществлялось поясом Роговского 8 с интегрирующей RC-цепочкой 9. Запуск развертки осциллографа 10 осуществлялся вспомогательным поясом Роговского 5. В изоляционной прокладке 2 был выполнен паз для перемещения индукционного датчика 6. 


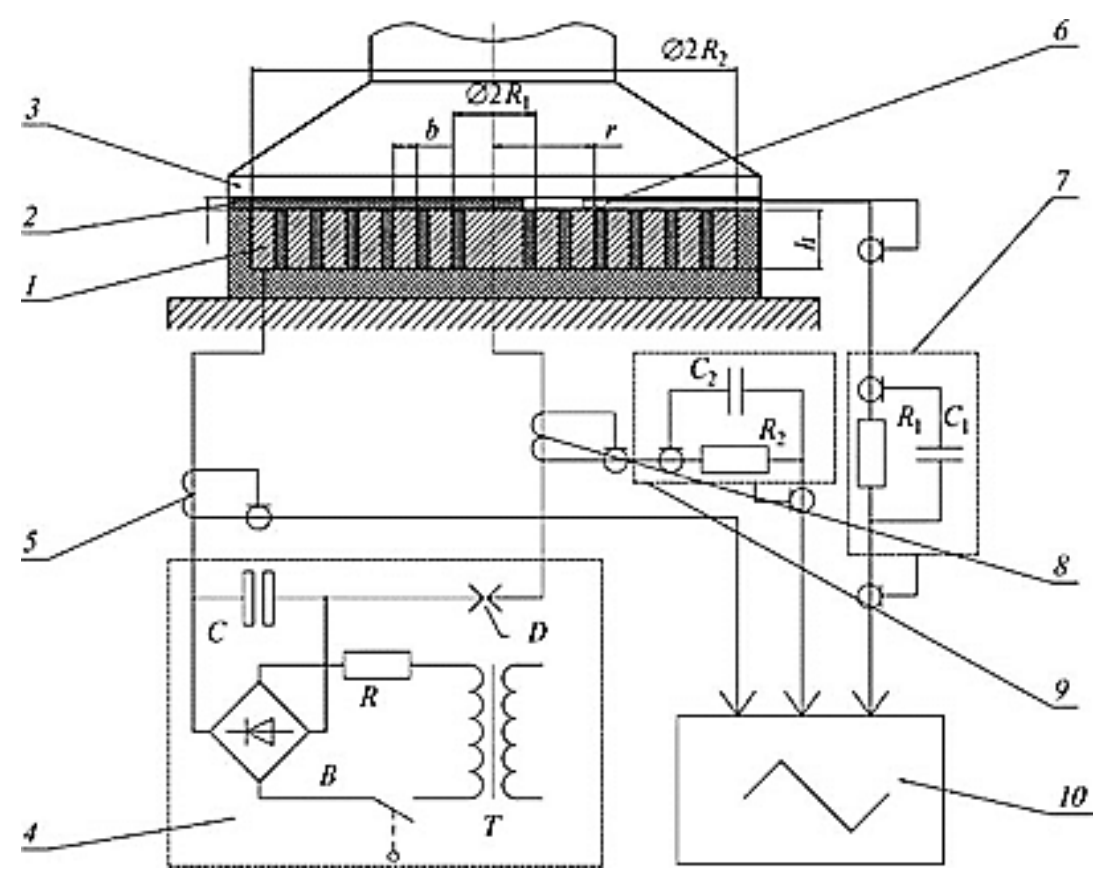

Рис. 5. Схема измерений напряженности магнитного поля:

1 - плоский спиральный индуктор; 2 - изоляционная прокладка; 3 - металлический подвижный элемент; 4 - магнитно-импульсная установка; 5 - пояс Роговского; запускающий развертку осциллографа; 6 - индукционный датчик; 7 - интегрирующая цепочка; 8 - пояс Роговского для измерения разрядного тока; 9 - интегрирующая цепочка; 10 - осциллограф

Измерения проводились для индуктора из медной шины шириной $b=3$ мм, высотой $h=14$ мм, с числом витков $n=13$. Внешний и внутренний радиусы спирали: $R_{2}=65$ мм, $R j=15$ мм. Толщина изоляционной прокладки была $A=1,75$ мм. С учетом изоляции спирали индуктора общий изоляционный зазор составлял примерно 2 мм. Подвижный элемент 3 был сделан из алюминия.

Средняя погрешность аппроксимации опытных данных составила около 13 \%. Данная зависимость может быть использована в практике расчетов технологического устройства и технологий МЭИФ. В компьютерной модели вместе с расчетом параметров разрядного тока данная зависимость позволит скорректировать давление магнитного поля идеального индуктора за счет «просачивания» поля в межвитковые зазоры и за счет движения подвижного элемента.

Разработана методика экспериментальной оценки давления магнитного поля плоского спирального индуктора в системе с подвижным элементом из хорошо проводящего материала. Экспериментальная методика построена на обработке измерений напряженности магнитного поля вдоль радиального направления спирали индукционным датчиком. Предложена система безразмерных параметров, определяющих напряженность магнитного поля. Данные параметры отражают геометрию спирали индуктора, величину изоляционного зазора между индуктором и подвижным элементом, частоту разрядного ток [7].

\section{ВЫВОДЫ}

Предлагается измерительный стенд для комплексной проверки расчетной модели по параметрам разрядного тока, электромагнитного давления на подвижный элемент и параметры давления в эластичной среде при деформировании заготовки в процессах МЭИФ. При этом сделана тарировка всех измерительных преобразователей.

Сопоставление математической модели по параметрам разрядного тока, среднего электромагнитного давления и давления в эластичной среде с результатами экспериментальных измерений показало, что значения погрешности прогнозирования данных параметров находятся в пределах значений точности задания параметров кривой деформационного упрочнения материала и динамического модуля объемного сжатия эластичной среды (полиуретана). 


\section{СПИСОК ИСПОЛЬЗОВАННОЙ ЛИТЕРАТУРЫ}

1. Вагин В. А. Методы исследования высокоскоростного деформирования металлов / В. А. Вагин, Г. А. Здор, В.С. Мамутов. - Минск : Наука и техника, 1990. - 207 с.

2. Мамутов В. С. Теория обработки металлов давлением. Компьютерное моделирование процессов листовой штамповки : учебное пособие / В.С. Мамутов, А. В. Мамутов .- СПб. : Издательство Политехнического университета, 2006. - 189 c.

3. Мамутов А. В. Технологии обработки материалов импульсным давлением : учеб. пособ. - СПб. : Издательство Политехнического университета, 2008. - 40 c.

4. Омаров Ш. А. Совершенствование предельного формоизменения при обработке материалов давлением / Ш. А. Омаров / Проблемы механики и управления : Материаль Международной конференции (16-22 сентября 2018 г. Махачкала). - М. : Издательство Московского университета. 2018. - 452 с., ил. - С. $306-310$.

5. Омаров Ш. А. Перспективные способы обработки материалов / Ш. А. Омаров // Актуальные проблемы обработки резанием современных материалов : мат. конф. гл. спец. маш. предпр. РД, препод. и аспиран. фил. ДГТУ. - Махачкала : ДГТУ, 2017. - С. 53-57.

6. Омаров Ш. А. Интенсификация формообразующих операций / Ш. А. Омаров // Достижения и проблемь развития технологии и машин обработки давлением : сб. науч. трудов ХХІ международной научнотехнической конференщии, (23-26 апреля 2018 г.). - Украина, г. Краматорск : ДГМА, 2018. - С. 93-99.

7. Омаров Ш. А. Разработка технологических процессов магнитно-эластоимпульсной формовки листовых материалов на основе математического моделирования энергосиловых и деформационных параметров : автореф. дис. канд. техн. наук /Ш. А. Омаров. - Санкт-Петербург : СПбГТУ, 1995. - 19 с.

8. Расчет взаимодействия сильных импульсных пульсирующих магнитных полей с металлами / П. В. Верещагин, Г. Н. Здор, В. С. Мамутов, Ш. А. Омаров. - Санкт-Петербург : СПбГТУ, 1992 г. - 15 с. - Деп. в ВНИИТЭМР, № $45-$ мш. 92.

\section{REFERENCES}

1. Vagin V. A. Metody issledovanija vysokoskorostnogo deformirovanija metallov / V. A. Vagin, G. A. Zdor, B.C. Mamutov. - Minsk: Nauka i tehnika, 1990. - 207 s.

2. Mamutov V. S. Teorija obrabotki metallov davleniem. Komp'juternoe modelirovanie processov li-stovoj shtampovki : uchebnoe posobie / V.S. Mamutov, A. V. Mamutov .- SPb. : Izdatel'stvo Politehnicheskogo universiteta, 2006. $-189 \mathrm{~s}$.

3. Mamutov A. V. Tehnologii obrabotki materialov impul'snym davleniem : ucheb. posob. - SPb. : Iz-datel'stvo Politehnicheskogo universiteta, 2008. - 40 s.

4. Omarov Sh. A. Sovershenstvovanie predel'nogo formoizmenenija pri obrabotke materialov davle-niem / Sh. A. Omarov / Problemy mehaniki i upravlenija : Materialy Mezhdunarodnoj konferencii (16-22 sentjabrja $2018 \mathrm{~g}$. Mahachkala). - M. : Izdatel'stvo Moskovskogo universiteta. 2018. - 452 s., il. - S. 306-310.

5. Omarov Sh. A. Perspektivnye sposoby obrabotki materialov / Sh. A. Omarov // Aktual'nye pro-blemy obrabotki rezaniem sovremenny materialov : mat. konf. gl. spec. mash. predpr. RD, prepod. i aspiran. fil. DGTU. Mahachkala : DGTU, 2017. - S. 53-57.

6. Omarov Sh. A. Intensifikacija formoobrazujushhih operacij / Sh. A. Omarov // Dostizhenija i pro-blemy razvitija tehnologii i mashin obrabotki davleniem : sb. nauch. trudov HHI mezhdunarodnoj nauchno- tehnicheskoj konferencii, (23-26 aprelja 2018 g.). - Ukraina, g. Kramatorsk: DGMA, 2018. - S. 93-99.

7. Omarov Sh. A. Razrabotka tehnologicheskih processov magnitno-jelastoimpul'snoj formovki li-stovyh materialov na osnove matematicheskogo modelirovanija jenergosilovyh i deformacionny paramet-rov : avtoref. dis. kand. tehn. nauk/Sh. A. Omarov. - Sankt-Peterburg : SPbGTU, 1995. - 19 s.

8. Raschet vzaimodejstvija sil'nyh impul'snyh pul'sirujushhih magnitnyh polej s metallami / P. V. Vereshhagin, G. N. Zdor, V. S. Mamutov, Sh. A. Omarov. - Sankt-Peterburg : SPbGTU, 1992 g. - 15 s. - Dep. v VNIITJeMR, № $45-$ msh. 92.

Омаров Ш. А. - канд. техн. наук, доц. ДГТУ;

Махмудов К. Д. - канд. техн. наук, проф. ДГТУ.

ДГТУ - Дагестанский государственный технический университет, г. Махачкала, Республика Дагестан, РФ.

E-mail: keger1963@mail.ru. 